\title{
EXTENDING PRODUCT FAMILY DESIGN METHODS TO PRODUCT-SERVICE-SYSTEM FAMILY DESIGN
}

\author{
Rosen, David (1,2); \\ Choi, Young Mi (1) \\ 1: Georgia Institute of Technology; \\ 2: Singapore University of Technology and Design
}

\begin{abstract}
Although product family design methods are well established, little research has focused on ProductService-System (PSS) family design. A PSS family design method is proposed in this paper that parallels methodology for designing product families. Separate platforms are proposed for products and for services. However, couplings between product and service platforms are identified and incorporated into the design method. Design problem formulations are proposed for PSS family platforms and for the PSS family itself, using a module-based approach, in contrast to a platform scaling approach. Alternative methods are investigated and compared for solving these problems. The application domain of Assistive Mobility (AM) is identified as a promising PSS family in this work. If smart technologies are integrated into AM devices, such as manual wheelchairs, powered wheelchairs, walkers, and rollators, then patient diagnosis and treatment, as well as device maintenance, services are enabled with these smart technologies, demonstrating that smart AM devices are a promising PSS family.
\end{abstract}

Keywords: Product-Service Systems (PSS), Product architecture, Design methodology, ProductService-System Family Design, Assistive Mobility

\author{
Contact: \\ Rosen, David \\ Georgia Institute of Technology \\ Mechanical Engineering \\ United States of America \\ david.rosen@me.gatech.edu
}

Cite this article: Rosen, D., Choi, Y. M. (2021) 'Extending Product Family Design Methods to Product-Service-System Family Design', in Proceedings of the International Conference on Engineering Design (ICED21), Gothenburg, Sweden, 16-20 August 2021. DOI:10.1017/pds.2021.417 


\section{INTRODUCTION}

Product-Service-Systems (PSS) are systems that provide services to people through, at least in part, a physical device. Smart phones are a quintessential example of a PSS. Many types of products can be viewed through the services they enable; hence, product development may benefit from a broader view of the product-service ecosystem in which they operate. As more "smart" products are developed, the importance of viewing products as PSS's increases since the services offered will become more important, likely being the key differentiator between product offerings from companies.

The paper proposes the concept of a PSS family and a PSS family design method. Although the field of product family design is well developed, methods from this field have been adopted incompletely in PSS design. Hence, the research gap addressed in this paper is the lack of a formal methodology for designing PSS families, and the PSS platforms from which they can be generated. In this paper, we propose a general design method for PSS families that combines methods from product family and PSS design fields. We begin by reviewing relevant literature in the product family, PSS design, and application domain fields. Then, we demonstrate the application of the method on a proposed family of smart wheelchairs. In the future, we plan to develop a more complete PSS family design methodology and a PSS family reasoning system as an implementation of that methodology.

The application domain of Assistive Mobility (AM) can be viewed as a large PSS family. AM devices, such as manual wheelchairs, powered wheelchairs, walkers, and rollators, are critically important to many people worldwide. Although the AM market is mature with well developed families of devices and service delivery mechanisms, the AM ecosystem seems highly fragmented with only modest coordination among actors, highly variable in service delivery quality and frequency, and lacking in adoption of innovative technologies. At present, the process of designing and provisioning mobility devices is currently very product-centric. Wheeled mobility devices could be much more innovative with useful integrated services that will make it easier to match the device to the user's needs. In this paper, we outline a proposed smart wheelchair PSS family with enabling technologies and potential services, as a limited example of an AM PSS family, and demonstrate that our proposed PSS family design method can help develop a PSS platform and generate candidate wheelchair PSS's.

\section{LITERATURE REVIEW}

\subsection{Product-Service-Systems}

Today, many customers pay for their interests based on capability or availability rather than purchasing physical artifacts as seen in the rise of shared bicycles, scooters, and cars. Companies, therefore, have been improving their strategies to retain customers by shifting from offering a product alone to a servicebased approach. The PSS concept, which was introduced in the late 1990s, is then one of the potential strategies (Tan et al., 2007). Typically, a PSS consists of physical objects and service units that relate to each other and its main focus is to provide functionality to the customer (Maussang et al., 2009). In this work, we focus on Product Oriented PSS's, where services are attached to products directly (Reim et al., 2015) to deliver value to customers (Westkämper et al., 2001).

Over the years, many researchers have introduced different PSS design approaches (Maussang et al., 2009; Vasantha et al., 2012; Haber and Fargnoli, 2017). Several groups have proposed service system design methods and software tools (Hara et al., 2009). In this approach, a function hierarchy with parameters is developed, activities are identified and connected into services, products and modules are identified, then functions are related to activities and to products to integrate everything together. The PSS approach has been applied also to software engineering (Rosen et al., 2017).

Although little literature uses the term "product-service-system family" (Sakao et al., 2020) some literature does discuss modularity in the context of service or PSS design (Eissens van der Laan et al., 2016; Fargnoli et al., 2019; Moon et al., 2011), service families (Voss and Hsuan, 2009), and some even propose a service platform approach (Cenamor et al., 2017). PSS modularization was presented in the context of Axiomatic Design and Design Structure Matrices to develop decoupled and reusable service modules (Fargnoli et al., 2019). Of note, Voss and Hsuan (2009) proposed a measure of service modularity which measures the degree of modularity in service architectures as a function of the total number of services, the number of unique services, and the number of service families. A related topic is that of customized PSS. Hara et al. (2009) provide a comprehensive survey of customized product, 
service, and PSS literature with extensive analysis. Moon et al. (2011) applied product family design methods to customized service design and proposed a cost model for evaluating service platforms.

\subsection{Product Family Design}

The product family design literature spans a wide range of topics including mass customization, design for product variety, designing a family of products, platform commonization, etc. Desired variety can be achieved within an entire product family through the use of a common platform. Martin and Ishii (2002) related a model of the market (through the market segmentation grid) to key product family characteristics of commonality, modularity, and standardization. From one perspective, product family design can be classified as either scale-based or module-based (Choudhury et al., 2011), implying that the family is generated by either scaling the product sizes or configuring predefined modules. In this work, we take a module-based approach.

Product platforms consist of the common components, modules, and technologies that are shared across a product family. Product platform identification, evaluation, and design have well established methods. Regarding service platforms, the identification of modular services that can be shared across a family of services is typically proposed as a service platform. For example, if a bank develops a set of checking account services, those services can serve as a platform for a service family that contains various banking options for a variety of customers (Moon et al., 2011). Despite considerable research in the last 10 years, methods for effectively identifying service modules and platforms are not as prevalent as for product modules and platforms.

Product and service platforms establish the shared elements from which PSS's and families can be generated. By sharing platform elements, PSS's can be developed faster and with fewer resources. In the module-based approach, products are configured by adding optional modules to a selected product platform. The identification of modules is critical in developing good platforms and options that enable designed variety. Different research groups have introduced methods for the identification of modules based on the functional descriptions of products (Stone et al., 2000), product strategies (Borjesson and Holtta-Otto, 2013), and what modules may mean in the context of additive manufacturing (Lei et al., 2016). A comprehensive view of module identification was provided in (Otto et al., 2016). Methods for platform development can be based on component relationships through Design Structure Matrix (DSM) reasoning (Stone et al., 2000), commonality (Newcomb et al., 1998), or costs (Kusiak et al., 2007). Metrics for commonality and standardization from these viewpoints have been attempted (Newcomb et al., 1998; Gershenson et al., 2003; Thevenot and Simpson, 2006).

\subsection{Designing Assistive Mobility Devices}

Research and development for new assistive products can be a significant cost, where small to mid-sized companies can spend over $9 \%$ of total sales on R\&D (US DOC 2003). The high cost, especially for smaller companies, makes it important to extract the highest level of benefit possible from this investment. Assistive products, including AM devices, generally occupy smaller, niche markets (Cowan and Turner-Smith, 1999). Products for these markets may not be mass produced and so the AM company does not gain the same cost reducing benefits that are associated with mass production. Instead they are often produced by a custom manufacturing process that is flexible and more efficient for smaller quantities. Lower sales volume due to smaller markets and higher costs of manufacturing increase the importance of ensuring that any product released has the best possible chance for success.

Compared to a typical consumer product the functionality of an assistive device is of primary importance. The device must not only be able to reliably execute its functionality, but it must also be matched to the specific capabilities of the user. An elaborate provisioning process has been developed around the delivery of many assistive devices to ensure a good match. The process of delivering an Assistive Mobility device generally follows eight main steps (Kairalla et al., 2016): Referral and Appointment; Prescription; Product Preparation; User Training; Assessment; Funding and Ordering; Fitting; Maintenance, Repairs and Follow-Up.

Users of assistive devices represent a continuum of abilities (Cook and Polgar, 2008), from those with slight to moderate disabilities who may have more general needs to those with more severe disabilities who may have very unique and specific needs. An assistive device (defined by the federal Individuals with Disabilities Education Act of 1990 (1990)) may therefore function well for one group of users but poorly for another group. This continuum can be a challenge for companies that design and manufacture 
assistive devices. Further adding to the challenge is that the capabilities will vary not only across different populations but also change for individuals as their needs evolve over time.

While the process of developing and delivering AM devices is mature, it is much more complicated than a typical consumer product. Where a consumer product may involve only a user and vendor, an assistive device involves many actors at different stages, including providers (physicians, physical/occupational therapists), payors (public/private insurers, government), suppliers (device manufacturers, resellers), and the clients (patient, caregivers or employers). This complexity leads to opportunities for improvements and efficiencies in the process of design and delivery, especially for transformative design innovations or incremental incorporation of new technologies such as smart devices, assistive robotics and novel human/machine interfaces (such as brain-computer interfaces, eye tracking and facial gesture recognition) (Schmeler et al., 2019), wearable computing devices, or "Internet of Things" (IoT) devices and applications (de Domingo, 2013). If AM devices become "smart," that enables the development of services that can be delivered through the device to improve service quality and timeliness.

\section{PSS FAMILY DESIGN METHOD}

The proposed PSS family design method is illustrated in Figure 1. The method was developed by combining module-based methods from product family design with methods from product-oriented PSS design. At the top of Figure 1, parallel efforts in PSS design and product family design define the start of the effort. The PSS family design method is meant to be used early in the design process so that maximum benefit can be gained across the entire family. However, information on expected product modules and components is needed, along with expected services and service scenarios. Additional research will be needed for earlier application of the method.

After some initial marketing and technical work, a comprehensive customer needs document is developed for the PSS family, indicated as step 1 in Figure 1. Indicators of customer value should be identified, called Receiver State Parameters (RSP) in service design literature. For each RSP, a function hierarchy is developed that identifies the decomposition of services to be offered in the PSS family. Associated with each function is a functional parameter that relates to the achievement of the RSP. The combination of the function hierarchy and the parameters embedded in it is called the View Model.

Under the PSS design focus, the next step is to develop service scenarios and identify the various activities and flows required to deliver the services. In this work, service scenarios are identified through standard service design methods (Vasantha et al., 2012). Activity sequences are developed for each scenario. The flows among the activities should be identified as well.

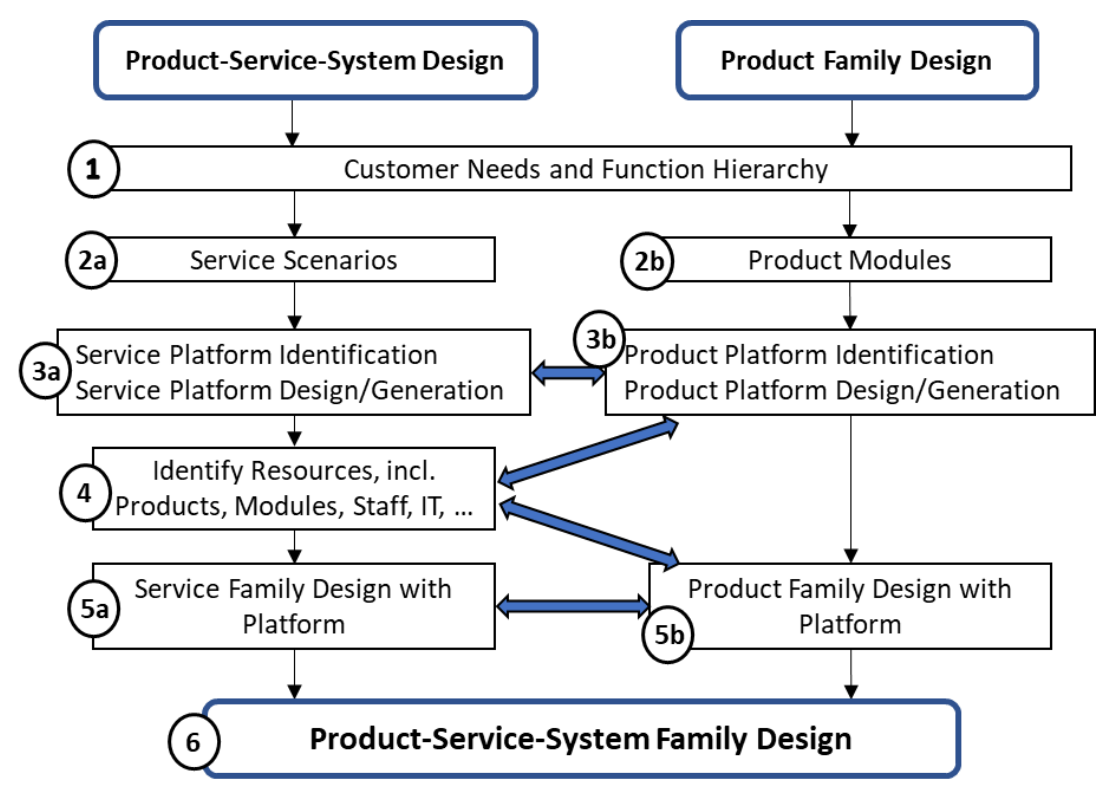

Figure 1. PSS family design method

On the product side, product modules should be identified as combinations of components that have some type of relationship among them. Typically, components in a product will be connected physically to one another. They may exchange energy (e.g. heat) or signals, even if not physically connected. 
Product modules are identified using DSM methods (Borjesson and Holtta-Otto, 2013; Newcomb et al., 1998) or similar clustering methods (Hansen and Rosen, 2019) and analyzed using commonality metrics (Gershenson et al., 2003, Thevenot and Simpson, 2006).

Step 3 addresses platform design for both the services and the products. Although the service and product platform design activities are illustrated as independent, they are coupled as indicated by the bold arrows that connect Steps 3-5. Product platform design is based on extensions of the product module identification methods and commonality metrics. Service platform design makes use of the modularization method proposed in (Fargnoli et al., 2019) and others. Associated with each service activity are various resources. Human staff, products or product modules, IT infrastructure, and organizations (e.g. companies) are examples of resources. Coupling arises in platform design, for example, when product module resources are required for an activity in the service platform. As a consequence, that product module must be included in the product platform; such associations are treated as constraints in the platform design methods.

In step 5, both the service family and the product family are designed with the platforms that were developed, with the result being a set of PSS's that share a common platform, which comprise the PSS family in step 6.

\section{ASSISTIVE MOBILITY PSS FAMILY DESIGN EXAMPLE}

An example of smart wheelchairs (WC) will demonstrate the application of the proposed PSS family design method. This example was developed based on commercially available WCs and service concepts proposed by the authors. As mentioned in Section 1, AM devices are not developed as PSS's, but, the authors believe, they could be. Thus, the consideration of WC's are platforms for service delivery is a novel contribution in this paper, as are the proposed services. The WC domain will include standard push WC's, powered WC's, and smart WC's that have built in sensors and communication devices. That is, the wheelchairs serve as the products and services will be delivered through the wheelchair. Services include wheelchair condition monitoring and maintenance, as well as patient monitoring and diagnosis. We start with an identification of the highest level functions that the proposed WC PSS family will perform. These include Transport Patient, Monitor Patient, Diagnose Patient, Monitor WC, and Maintain WC. Of these, the primary function that will be common to all PSS's in the family is (of course) Transport Patient. An example view model for this function is shown in Figure 2, with a top-level RSP of Safe \& Secure Mobility identified. Associated with each sub-function is either a more specific RSP or a Function Parameter (FP). An example activity network is included for WC maintenance, shown as a UML diagram. Resources are indicated beneath each activity as notes, similar to an IDEF0 diagram. In some cases, optional resources are listed (e.g., either Technician or Caregiver can inspect the WC); the bookkeeping necessary to treat the resources properly is not illustrated in the figure.

At present, companies offer services to select and fit a patient to a WC, maintain the WC, and upgrade the WC with new capabilities. These services are provided through phone calls, web-sites, and technician visits. By adding sensors to the WC, we believe that additional services can be provided. Furthermore, these services will be delivered through websites with considerable back-end information technology (IT) that collects sensor data, analyzes it, and notifies appropriate personnel when the need arises. The back-end IT infrastructure could take the form of a database that requires humans to periodically check sensor readings, digital twins of each WC and patient to keep their states up-to-date, along with some decision making capabilities to notify technicians, physical therapists, occupational therapists, caregivers, or physicians, as appropriate.

Continuing with the PSS family design method, we can further analyze patient needs and propose some service scenarios. Thinking ahead, while these service scenarios are developed, corresponding WC components should be identified as resources that enable those services. A basic service could include periodically notifying the patient's caregiver that the WC should be inspected, where the notification could be a phone call or text message. An alternative is to monitor WC status through sensors on the WC and identify maintenance needs through condition-based monitoring. Then, either the caregiver could be notified or a repair technician could be notified to arrange a visit to fix the WC. Services related to the patient could be similar; sensors on the WC could monitor patient vital signs (e.g., pulse-oxygen sensor) or their operation of the WC. If their ability to operate the WC seems to be degrading, then messages could be sent to their occupational therapist, physical therapist, or physician, as appropriate. 


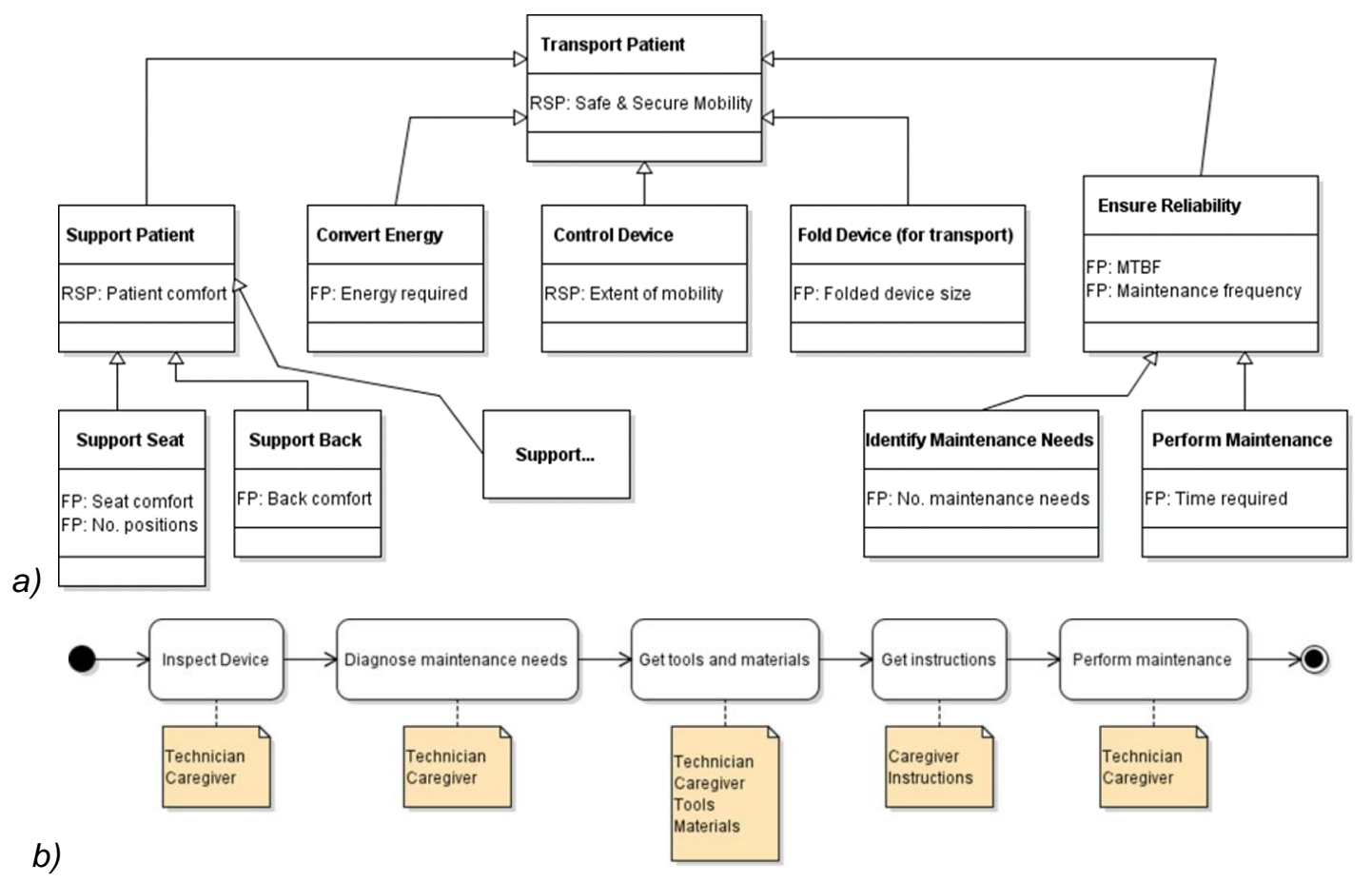

Figure 2. a) Function hierarchy for transport patient service, with functional parameters, $R S P$ safe \& secure mobility, and b) example activity sequence.

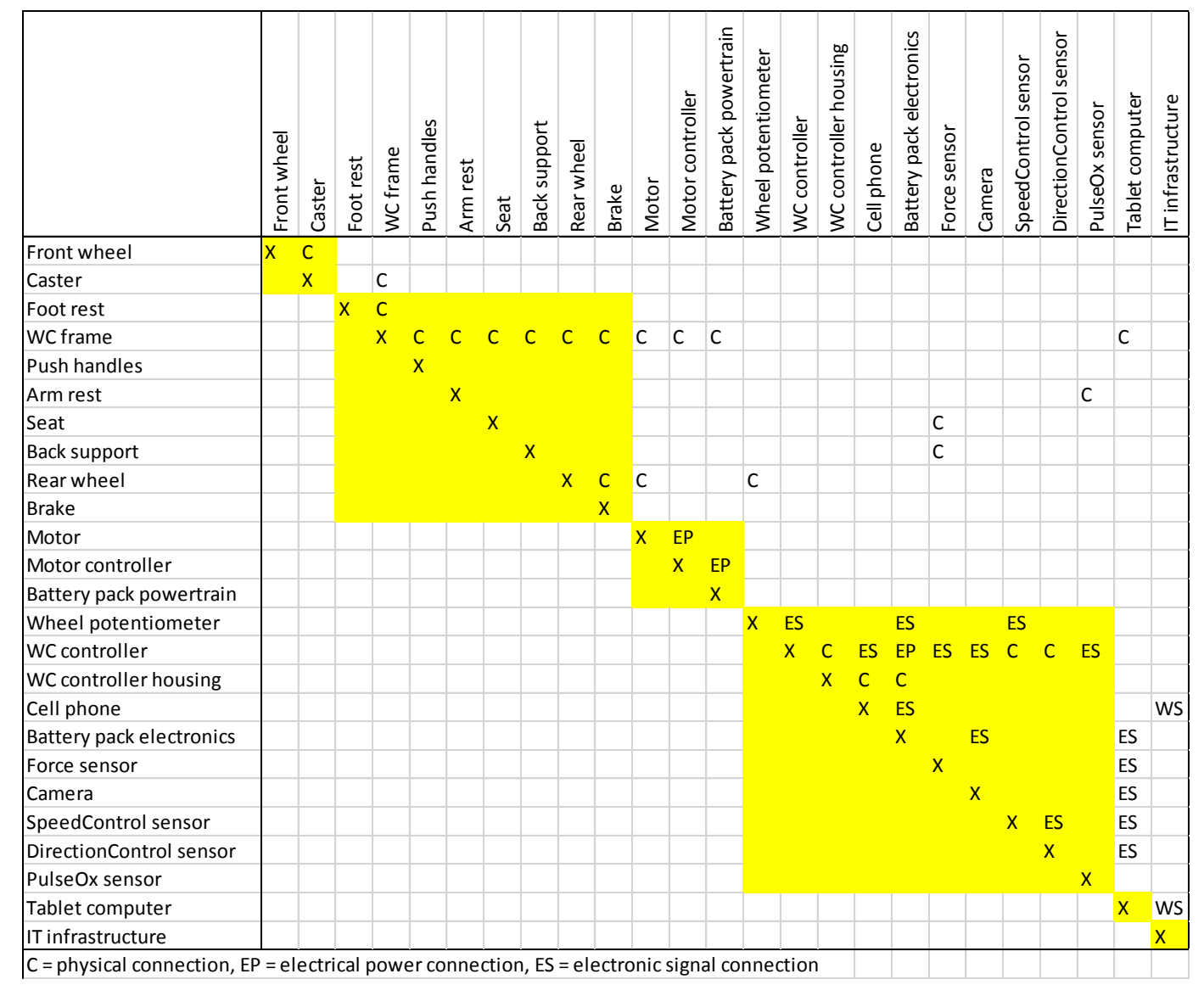

Figure 3. Design structure matrix with one set of possible wheelchair modules

Components needed on the WC to support these services include sensors to measure wheel rotations and rear wheel bearing status (e.g., wheel potentiometers), a pulse-oxygen sensor for patient vitals, a sensor for WC speed, a sensor for WC direction, sensors to determine patient posture (e.g., force sensors in the WC seat and back-rest), battery power for the sensors, and devices that communicate sensor data to a 
central site. We will use a cell phone or a tablet computer for communications. Note that the phone or computer could also be used for WC controls, for local analysis of sensor data, and other tasks.

A standard push WC consists of a frame, rear wheels, front wheels on casters, footrests, armrests, push handles, a seat, a back, and a brake. Powered WC's have a motor, a motor controller, a WC controller, and a battery pack. Additional components were identified for the various services. We assume that sensors are connected to the WC controller, which consists of electronics and a housing. Connections may be via wiring or wireless (e.g., Bluetooth).

After identifying services, activities, and components, platforms should be identified for the product and the services. These platforms should be consistent as well, meaning that any required resource for an activity in the service platform must be included in the product platform. Many methods have been developed for finding product platforms, including DSM methods, methods based on commonality considerations, and cost-based methods. We will use standard DSM analysis of connections, both physical and electronic, among components to identify modules in this paper. An example set of modules, based on the components described, is shown in Figure 3. Note that in our work, DSM matrices are symmetric so only the connections in the upper matrix region are shown. The large module in the upper left consists of the frame and standard components connected to the frame. For a powered WC, the 3-component module in the middle includes the motor, controller, and battery. To support the various services, a large module was defined to include the sensors and WC controller. In this module set, a cell phone is assumed to be the default communication device, while the tablet computer is an upgrade option. IT infrastructure exists but is not bundled with any other components. Note that four types of connections were used for DSM analysis: C for a physical connection between components, EP for electrical power, ES for an electronic signal, and WS for a wireless signal.

The main types of services to be provided were identified as the primary functions earlier: Monitor Patient, Diagnose Patient, Monitor WC, and Maintain WC. The means and sophistication of service delivery will lead to many specific services delivered with various levels of automation. For the purposes of this example, we have developed 35 activities from which services can be configured, including Notify Caregiver, Obtain Tools and Materials, Diagnose Patient Health Status, and Perform Training. To generate specific services, these activities are organized into sequences and specific resources are assigned to each activity. We proposed four competing organizations to offer different service combinations, where the organizations do not cooperate. That is, each activity sequence is performed by only one organization. From these 35 activities, we generated all possible activity sequences using alternative resources, which resulted in 113 sequences, including sequences of only one activity. Of these, 71 consisted of two or more activities. These are illustrated as the directed graph in Figure 4.



Figure 4. All activity sequences in the PSS family. 
Notify Caregiver $\rightarrow$ Obtain Tools and Materials $\rightarrow$ Obtain Instructions $\rightarrow$ Perform Maintenance

Notify Technician $\rightarrow$ Obtain Tools and Materials $\rightarrow$ Perform Maintenance

Notify Occupational Therapist $\rightarrow$ Diagnose Patient Health Status

Notify Occupational Therapist $\rightarrow$ Diagnose Patient Training Needs $\rightarrow$ Perform Training

Notify Physical Therapist $\rightarrow$ Diagnose Patient Health Status

Figure 5. Example service platform consisting of 5 activity sequences.

From these activity sequences, a service platform can be selected by identifying activity sequences that are repeated, that is, that are common across more than one service in Figure 4. Figure 5 shows the service platform selected for a PSS family that will provide a variety of maintenance, monitoring, and diagnosis services. One service provider company was selected to provide all services in the platform and IT digital twin infrastructure was selected. Although this represents a significant investment by the company, that investment can be leveraged across many services. A cost-based platform identification method would be needed to evaluate its efficacy.

Many optional service modules can be identified readily from Figure 4. For WC maintenance services, if sufficient WC sensor data are collected, inspection and diagnosis can be performed automatically by the IT digital twin. Then, either the caregiver or the technician can be notified, depending on which service has been selected by the customer. Prior to notifying the occupational or physical therapist, WC sensor data, and potentially patient data, can be analyzed to sense patient operation competence of the WC or to sense patient health status. Those activity sequences could be offered as optional modules.

From this service platform, product components can be identified that must be in the product platform. In this case, only a cell phone is required for some of these services. From Figure 3, the product platform can be developed. The large module centered on the WC frame is selected for the platform, along with the module consisting of casters and front wheels. For the electronics, the platform will include a module containing components from the wheel potentiometers through the battery pack electronics (5 components). With these modules selected for the platform, the constraint on including the cell phone is satisfied.

For the optional service modules identified previously, additional components can be identified that would comprise corresponding product modules to be packaged with the service modules. Wheel potentiometers, speed sensors, direction sensors, the WC controller and housing, battery packs, etc. can be packaged into a sensor and diagnosis module. The motor, motor controller, and battery pack form a powered WC module. The tablet computer can be swapped for the cell phone. For sensing patient vitals, a pulse-ox sensor can be attached to an armrest and connected to the WC controller. The IT infrastructure is treated separately.

Table 1. Selected PSS family

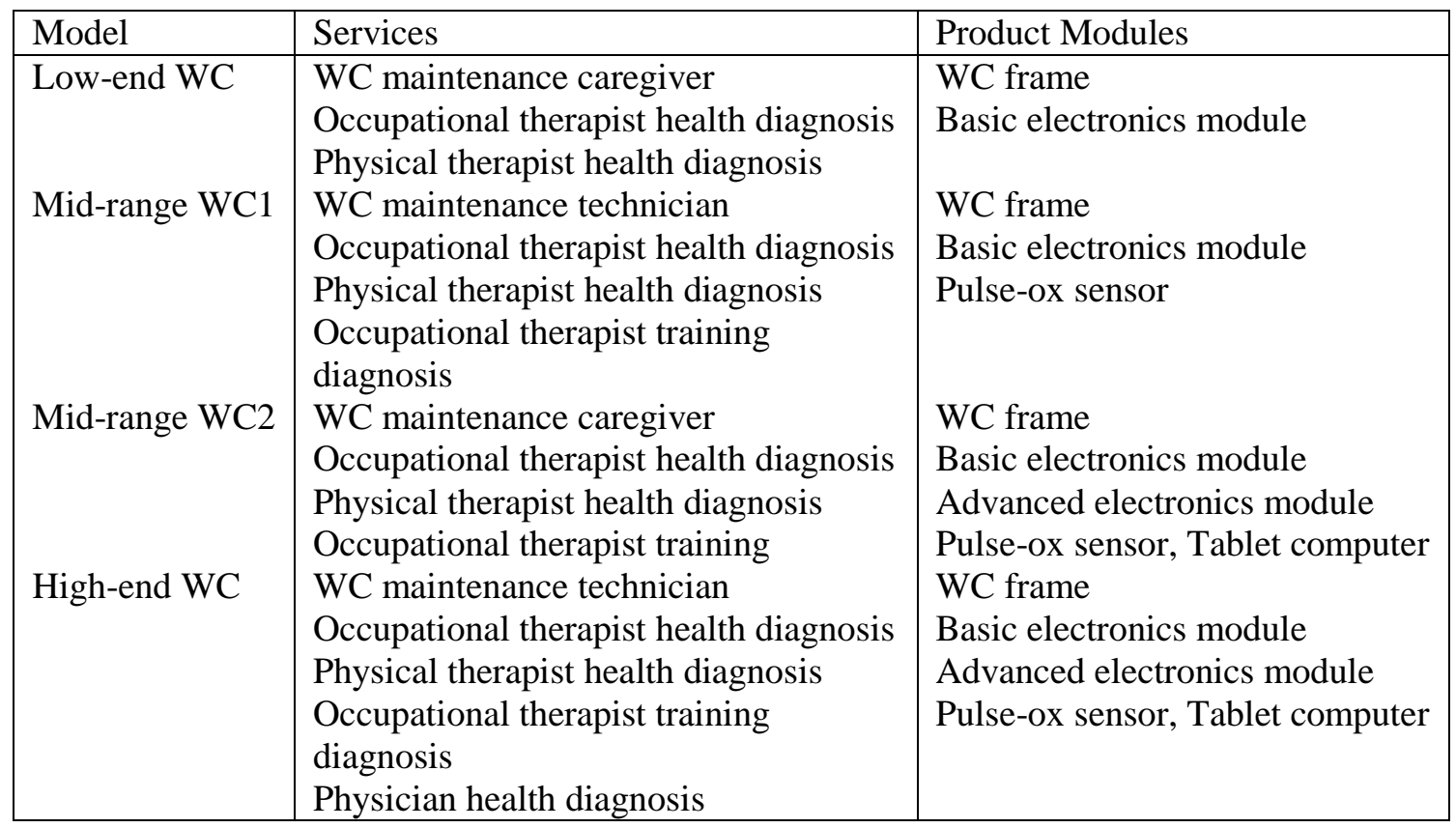


Given the platform and the desired range of services to be offered, a PSS family can be configured. All combinations of optional modules can be generated to form the entire PSS family design space. From these alternatives, the designer can select several to comprise the PSS family, depending on how they would like to cover and segment the market. For our purposes, we have selected the four PSS's shown in Table 1: one low-end WC PSS with basic maintenance and health diagnosis, two mid-range WC models that offer one additional service, and a high-end WC with a tablet computer and the opportunity to have a physician perform health diagnosis. These choices cover the low and high ends of the market and provide two intermediate choices with different levels of service. Of course, these 4 PSS's are merely a sampling of the entire set of possible WC PSS's.

\section{CONCLUSIONS}

A Product-Service-System family design method was proposed in this paper that parallels methodology for designing product families. Separate platforms were proposed for products and for services. However, couplings between product and service platforms were identified and incorporated into the design method. Design methods from the literature were proposed and adapted for PSS family platforms and for the PSS family itself. Alternative methods were investigated and compared for solving these problems. The application domain of Assistive Mobility (AM) was identified as a promising PSS family to investigate. To illustrate the PSS family design method, an example was explored on smart wheelchair design, with patient services and associated technologies proposed. Results demonstrate the potential of the PSS family design method in developing service and product modules and platforms and in configuring a set of PSS's that comprise a PSS family. We conclude that that concept of a PSS family provides an important framework for systematically developing a suite of PSS's that are appropriate for an identified market.

As this is only a first step, considerable research is needed to more fully explore methods for each step of the PSS family design method. A consideration of costs and customer value is critically important so that the benefits of a PSS family approach can be more thoroughly demonstrated. Design costs, manufacturing costs, and cost savings should be analyzed using realistic market conditions to demonstrate that the platform approach is justified. Customer value, in terms of effective functionality as well as increased usability, increased satisfaction, reduced abandonment rates and reduced stigma, should be evaluated to demonstrate that a PSS family approach is beneficial compared to PSS's developed individually. Furthermore, our study was limited to a module-based approach to PSS design. A scale-based approach should be investigated also.

\section{REFERENCES}

Borjesson F. and Holtta-Otto K. (2013). "A module generation algorithm for product architecture based on component interactions and strategic drivers." Research in Engineering Design, 25(164): 21.

Cenamor J., Ronnberg Sjodin D., and Parida V. (2017) “Adopting a platform approach in servitization: Leveraging the value of digitalization," Int. J. Production Economics, 192: 54-65.

Choudhury, S., Messac, A., and Khire, R.A., (2011) "Comprehensive Product Platform Planning (CP3) Framework,” ASME J. Mech. Des., 133(10), 101004.

Cook, A.M. and Polgar, J.M. (2008). Assistive Technologies: Principles and practice (3rd ed.). St. Louis: Mosby Elsevier.

Cowan, D. and A. Turner-Smith, (1999) "The Role of Assistive Technology in Alternative Models of Care for Older People," in With Respect to Old Age - Research Volume 2. 1999.

de Domingo K. (2013) “Assistive technologies for cognition: Perspectives on funding," Perspectives on Neurophysiology and Neurogenic Speech and Language Disorders, 22(2): 84-89.

Eissens-van der Laan M., Broekhuis M., van Offenbeek M., and Ahaus K. (2016) "Service decomposition: a conceptual analysis of modularizing services,” Int. J. Oper. Prod. Manag., 36(3):308-331.

Fargnoli M., Haber N., and Sakao T. (2019) PSS Modularization - A Customer Driven Integrated Approach, International Journal of Production Research, 57(13): 4061-4077.

Gershenson, J. K., Prasad, G. J., and Zhang, Y. (2003) "Product Modularity: Measures and Design Methods,” J. Engineering Design, 15(1), pp. 33-51.

Haber, N. and Fargnoli M. (2017) "Design for Product-Service Systems: A Procedure to Enhance Functional Integration of Product-Service Offerings.” International Journal of Product Development, 22(2): 135-164.

Hansen, J-T. and Rosen, D.W. (2019) “A Product Family Design Method for Configuration and Spatial Layout Requirements,” J. Computing and Information Science in Engineering, 19: 031006. 
Hara T., Arai T., and Shimomura Y. (2009), “A CAD system for service innovation: integrated representation of function, service activity, and product behavior," Journal of Engineering Design, 20:4, 367-388.

Individuals with Disabilities Education Act of 1990, Public Law 101-476, https://sites.ed.gov/idea/.

Kairalla, J.A., Winkler, S.L., and Feng, H. (2016) "Understanding the Provision of Assistive Mobility and Daily Living Devices and Service Delivery to Veterans After Stroke," American Journal of Occupational Therapy, 70, 7001290020. Dicianno, B.E., Joseph, J., Eckstein, S., Zigler, C.K., Quinby,

Kusiak, A., Smith, M.R., and Song, Z. (2007) "Planning product configurations based on sales data," IEEE Transactions on Systems, Man, and Cybernetics: Part C, 37(4), 602-609.

Lei, N., Yao, X., Moon, S.K., and Bi, G. (2016) “An additive manufacturing process model for product family design,” J. Engineering Design, 27(11): 751-767.

Martin, M. V. and K. Ishii (2002). "Design for Variety: Developing Standardized and Modularized Product Platform Architecture." Research in Engineering Design, 13(4): 213-235.

Maussang N., Zwolinski P., and Brissaud D. (2009), "Product-service system design methodology: from the PSS architecture design to the products specifications," Journal of Engineering Design, 20(4), 349-366.

Moon S.K., Shu J., Simpson T.W., and Kumara S.R. (2011) “A module-based service model for mass customization: service family design,” IIE Transactions, Vol. 43 No. 3, pp. 153-163.

Newcomb, P.J., Bras, B.A., and Rosen, D.W. (1998) "Implications of Modularity on Product Design for the Life Cycle," ASME J. of Mechanical Design. Vol. 120, No. 3, pp. 483-90, September.

Otto, K., Holtta-Otto, K., Simpson, T.W., Krause, D., Ripperda, S., and Moon, S.K. (2016) “Global Views on Modular Design Research: Linking Alternative Methods to Support Modular Product Family Concept Development," ASME J. Mechanical Design, 138: 071101.

Reim, W., Parida, V., and Örtqvist, D., (2015), "Product-Service Systems (PSS) business models and tactics-a systematic literature review," Journal of Cleaner Production, 97, 61-75.

Rosen, D.W., Na Ayutthaya, D.H., and Koomsap, P. (2017) “Additive and digital manufacturing design tools: an application of product-service system design," Asia-Design Engineering Workshop, Seoul, South Korea, Dec. 11-12.

Sakao T, Hara T, Fukushima R (2020) “Using Product/Service-System Family Design for Efficient Customization with Lean Principles: Model, Method, and Tool," Sustainability, 12, 5779. https://dx.doi.org/10.3390/su12145779

Schmeler, E.J., M.R., Schein, R.M., Pearlman, J., and Cooper, R.A. (2019) "The future of the provision process for mobility assistive technology: a survey of providers," Disability and Rehabilitation: Assistive Technology, 14:4, 338-345.

Simpson, T.W., Bobuk, A., Slingerland, L.A., Brennan, S., Logan, D., and Reichard, K. (2012). "From user requirements to commonality specifications: an integrated approach to product family design." Research in Engineering Design, 23(119): 13.

Stone, R. B., Wood, K. L., and Crawford, R. H. (2000). "A Heuristic Method for Identifying Modules for Product Architectures." Design Studies, 21(1): 27.

Tan, A., McAloone, T. C., \& Gall, C., (2007), "Product/Service-System development: an explorative case study in a manufacturing company", In 16th International Conference on Engineering Design. Design Society.

Thevenot, H. J. and T. W. Simpson (2006). "Commonality Indices for Product Family Design: A Detailed Comparison." Journal of Engineering Design 17(2): 21.

US Department of Commerce (2003) Technology Assessment of the US Assistive Technology Industry. Available from: https://www.bis.doc.gov/index.php/documents/technology-evaluation/60-technologyassessment-u-s-assistive-technology-industry-2003.

Vasantha G.V.A., Roy R., Lelah A., and Brissaud D. (2012), “A review of product-service systems design methodologies", Journal of Engineering Design, 23(9), 635-659.

Voss C.A. and Hsuan J. (2009) "Service Architecture and Modularity,” Decision Sciences, 40(3):541-569.

Westkämper E., Alting L., and Arndt G. (2001), "Life cycle management and assessment: approaches and visions towards sustainable manufacturing (keynote paper)", Proc. Inst. Mech Engr Part B, 215(5):599-626. 